\title{
Wilms' tumor gene WT1-shRNA as a potent apoptosis-inducing agent for solid tumors
}

\author{
NAOYA TATSUMI $^{1}$, YUSUKE OJI ${ }^{2}$, NAOKO TSUJI ${ }^{1}$, ASAKO TSUDA $^{1}$, MARI HIGASHIO $^{1}$, \\ SAYAKA AOYAGI ${ }^{1}$, IKUYO FUKUDA $^{1}$, KEN ITO $^{1}$, JUNYA NAKAMURA ${ }^{1}$, SATOSHI TAKASHIMA ${ }^{1}$, \\ YAYOI KITAMURA $^{1}$, SAORI MIYAI ${ }^{1}$, TANYARAT JOMGEOW ${ }^{1}$, ZHEYU LI $^{1}$, TOSHIAKI SHIRAKATA ${ }^{1}$, \\ SUMIYUKI NISHIDA $^{3}$, AKIHIRO TSUBOI ${ }^{3}$, YOSHIHIRO OKA ${ }^{4}$ and HARUO SUGIYAMA ${ }^{1}$
}

\begin{abstract}
Departments of ${ }^{1}$ Functional Diagnostic Science, and ${ }^{2}$ Biomedical Informatics, Osaka University Graduate School of Medicine, 1-7 Yamada-Oka, Suita, Osaka; Departments of ${ }^{3}$ Cancer Immunotherapy, and ${ }^{4}$ Molecular Medicine,

Osaka University Graduate Schoolof Medicine, 2-2 Yamada-Oka, Suita, Osaka 565-0871, Japan
\end{abstract}

Received August 13, 2007; Accepted October 19, 2007

\begin{abstract}
Wilms' tumor gene WT1 is overexpressed in leukemia and various types of solid tumors and plays an important role in leukemogenesis and tumorigenesis. We tested apoptosis-inducing ability of short hairpin RNAs targeting exon 5 (shWTE5), exon10 (shWTE10) and 3'UTR (shWT3U) of the WT1 gene. Among the three WT1shRNAs, since shWTE5 most effectively induced apoptosis, its ability as an apoptosis-inducing agent was intensively examined. shWTE5 induced mitochondrial damage and resultant apoptosis in five WT1-expressing solid cancer cells originated from gastric (AZ-521), lung (LU99B), ovarian (TYKnuCPr) cancers, fibrosarcoma (HT-1080) and glioblastoma (A172). Moreover, shWTE5 significantly enhanced apoptosis induced by chemotherapeutic agents, doxorubicin (DOX) and etoposide (ETP), or by death ligand TRAIL in all of the four solid tumor cells examined (HT-1080, LU99B, TYK and A172). Transduction of one each of WT1 isoforms with exon 5 [17AA(+)KTS(+) and 17AA(+)KTS(-)] prevented mitochondrial damage induced by ETP or TRAIL and inhibited apoptosis. These results showed that shWTE5 induced apoptosis through the suppression of the WT1 isoform with exon 5. Furthermore, shWTE5 increased expression of proapoptotic Bak and Bax proteins and decreased antiapoptotic Bcl-xL and Bcl-2 proteins in WT1expressing HT-1080 cells, indicating that WT1 isoforms with exon 5 might play an antiapoptotic role through
\end{abstract}

Correspondence to: Dr Haruo Sugiyama, Department of Functional Diagnostic Science, Osaka University Graduate School of Medicine, Yamada-Oka, Suita, Osaka 565-0871, Japan

E-mail: sugiyama@sahs.med.osaka-u.ac.jp

Abbreviations: shRNA, short hairpin RNA

Key words: Wilms' tumor gene, WT1, shRNA, apoptosis, solid cancer regulation of Bcl-2 family genes in solid tumor cells. The results presented here demonstrated that WT1-shRNA targeting exon 5 should serve as a potent anti-cancer agent for various types of solid tumors.

\section{Introduction}

The WT1 gene was originally isolated as a tumor suppressor gene responsible for Wilms' tumor, a neoplasm of the childhood (1). The WT1 gene encodes a protein with four zinc fingers, produces four isoforms [17AA $(+) \mathrm{KTS}(+)$, 17AA(+)KTS(-), 17AA(-)KTS(+) and 17AA(-)KTS(-)] by alternative splicing at two sites (17AA in exon 5 and KTS in exon 9), and is considered to be involved in transcriptional regulation of the genes such as PDGF-A chain (2), CSF-1 (3), IGF-II (4), IGF-IR (5), RAR- $\alpha$ (6), amphiregulin (7), and in RNA metabolism (8-10). The wild-type WT1 gene is overexpressed in primary human leukemia (11) and a wide variety of solid tumors, including lung (12), colon (13), esophageal $(14)$, breast $(15,16)$, thyroid $(17)$, pancreatic ductal cancer (18), head and neck squamous cell carcinoma (HNSCC) (19), astrocytic tumors (20), and bone and softtissue sarcoma (21). Moreover, a) high expression levels of WT1 mRNA correlated with poor prognosis in leukemia (11), breast cancer (16), and soft-tissue sarcoma (22) and with high tumor-stage in testicular germ-cell tumors (23) and HNSCC (19); b) growth of WT1-expressing leukemia and solid tumor cells was inhibited by the treatment with WT1 antisense oligomers $(18,20,24-26)$; c) constitutive expression of WT1 17AA(+)KTS(+) isoform blocked the differentiation of $32 \mathrm{D} \mathrm{cl3}$ myeloid progenitor (27) and normal myeloid cells (28) and induced their proliferation in response to granulocyte colony-stimulating factor (G-CSF); d) bone marrow cells with high expression levels of WT1 tended to develop into leukemia in the 7,12-demethylbenz[a]anthracene (DMBA)-induced rat leukemia (29); e) Lck promoter-driven WT1 17AA(+)KTS(-) isoform-transgenic mice showed block of differentiation in $\mathrm{T}$ lymphoid progenitor cells (30); and f) WT1 17AA(-)KTS(-) isoform induced cytoskeletal changes and promoted in vitro invasion 
through regulation of expression of actin binding proteins (31). Based on these findings, we had proposed that the wild-type WT1 gene played an oncogenic role rather than a tumor-suppressor function in tumorigenesis of various types of cancers (32).

Apoptosis and growth arrest are the most important intracellular controls in cancer cells (33). Since many physiological growth control mechanisms that govern cell proliferation and tissue homeostasis are linked to apoptosis, it is considered that resistance of cancer cells to apoptosis is an essential feature of cancer development. Antiapoptotic Bcl-2 family members, $\mathrm{Bcl}-2$ and $\mathrm{Bcl}-\mathrm{xL}$, which have the potential to inhibit mitochondrial permeabilization, are overexpressed in several cancers such as lung (34) and breast cancer (35). Expression of the inhibitor of apoptosis protein (IAP) family members including survivin appears to be common in several malignancies such as non-small cell lung cancer (36). Hence, a potent apoptosis-inducing agent is needed to overcome the resistance of cancer cells to apoptosis and develop more effective anticancer therapy.

Recently, we demonstrated that among the four WT1 $17 \mathrm{AA}(+)$ isoforms, WT1 $17 \mathrm{AA}(+)$ isoforms [17 AA $(+)$ $\mathrm{KTS}(+)$ and 17AA(+)KTS(-)] were dominantly expressed in primary leukemia regardless of subtypes and exerted their antiapoptotic functions through stabilization of mitochondrial membrane potential in leukemia cells and that knockdown of WT1 17AA(+) isoforms by short hairpin RNA induced apoptosis in them (37). These results showed that shRNA targeting WT1 17AA(+) isoforms (WT1-shRNA) was a potent apoptosis-inducing agent for leukemia. In contrast to dominant expression of WT1 17AA(+) isoforms in leukemia, their expression in solid tumors is minor $(12,19,21)$. Therefore, it remains unclear whether WT1-shRNA could also induce apoptosis in solid tumors and be a potent apoptosis-inducing agent for them.

In the present study, we demonstrate that WT1-shRNA induces mitochondrial damage and the resultant apoptosis in WT1-expressing solid tumor cells and that it also enhances apoptosis induced by chemotherapeutic agents, DOX and ETP, or by death ligand TRAIL.

\section{Materials and methods}

Cell lines and culture conditions. Five WT1-expressing solid cancer cell lines, fibrosarcoma HT-1080, lung cancer LU99B, ovarian cancer TYKnu.CPr (TYK), gastric cancer AZ-521, glioblastoma A172, and three WT1-non-expressing solid cancer cell lines, gastric cancer MKN28, cervical cancer HelaAG and lung cancer PC-14 were cultured in Dulbecco's modified essential medium supplemented with $10 \%$ fetal bovine serum (FBS).

Reagents. zVAD-fmk (broad-caspase inhibitor), Ac-LEHD$\mathrm{CHO}$ (inhibitor for caspases-9), Ac-DEVD-CHO (inhibitor for caspase-3), and Ac-IETD-CHO (inhibitor for caspase-8) (Peptide Institute Inc., Osaka, Japan) were used to inhibit caspase activity at the concentrations of $50 \mu \mathrm{M}$. Doxorubicin (DOX, Sigma Chemical Co., Steinheim, Germany) and Etoposide (ETP, Wako, Osaka, Japan) were used to induce apoptosis through activation of the intrinsic apoptosis path- way. Concentrations of DOX used were $2 \mu \mathrm{M}$ for HT-1080, TYK, A172 and PC-14, and $100 \mathrm{nM}$ for LU99B unless otherwise indicated. Concentrations of ETP used were $25 \mu \mathrm{M}$ for HT-1080, TYK, A172 and PC-14, and $12.5 \mu \mathrm{M}$ for LU99B unless otherwise indicated. Soluble Tumor Necrosis Factor (TNF)-related apoptosis-inducing ligand, TRAIL (PeproTech EC, London, UK) was used to induce apoptosis through activation of the extrinsic apoptosis pathway at the concentrations of $25 \mathrm{ng} / \mathrm{ml}$ for HT-1080, LU99B, TYK, A172 and PC-14 unless otherwise indicated. The enzyme substrates Ac-DEVD-AFC (BIOBOL, Tebu, France) and FAM-LEHD-FMK (Serologicals, Norcross, GA) were used to detect activities of caspase-3 and -9 , respectively.

Antibodies. Monoclonal anti-WT1 (6F-H2, Dako Cytomation, Carpinteria, CA), anti-GAPDH (Chemicon International, Temecula, CA), anti-Bak (Oncogene Research Products, Boston, MA) and anti-Bcl-xL (Chemicon) antibodies, and polyclonal anti-Bax (Santa Cruz Biotechnology, Santa Cruz, CA), anti-Bcl-2 (Santa Cruz Biotechnology) and anticytochrome c (Santa Cruz Biotechnology) antibodies were used as the first antibodies. Goat anti-rabbit and anti-mouse IgG antibodies conjugated with alkaline phosphatase (Santa Cruz Biotechnology) were used as the secondary antibodies in Western blot analysis.

shRNA and transfection. To prepare shRNA vectors targeting Exon 5 (17AA sequence), Exon 10, and 3'UTR of the WT1 mRNA and shRNA targeting luciferase mRNA, chemically synthesized oligonucleotides encoding dsRNA directing against (5'-AGCTCCAGCTCAGTGAAATGGACAGAA GGG-3'), (5'-AAACATGACCAAACTCCAGCTGGCGCT TTG-3'), and (5'-AAGTACTAGATGCATCACTGGGTG TTGATC-3') in WT1 mRNA, and (5'-ACATCACGTAC GCGGAATACTTCGAAATGT-3') in luciferase mRNA (Japan BioScience, Saitama, Japan) (Fig. 1A) were annealed and inserted into tRNA-shRNA expression vector piGENE tRNA Pur (Clontech, CA). For transient expression of shRNA, HT-1080, AZ-521, LU99B, TYK, A172, MKN28, HelaAG and PC-14 cells $\left(3 \times 10^{4}\right.$ cells $/ 2 \mathrm{ml} /$ well in 6 -well plates) were transfected with $2 \mu \mathrm{g}$ of plasmid DNA using Fugene 6 (Roche, Indianapolis, IN), according to the manufacturer's instruction.

Western blot analysis. Cells were washed twice with PBS and lysed with 2X Laemmli's SDS sample buffer. Proteins were separated by SDS-PAGE and transferred to Immobilon polyvinylidene difluoride membrane (Millipore Corp., Bedford, MA). After blocking of non-specific binding, immunoblots were incubated with the first antibody followed by incubation with appropriate anti-rabbit or anti-mouse IgG antibody conjugated with alkaline phosphatase and visualized using BCIP/NBT kit (Nacalai Tesque, Kyoto, Japan).

RNA isolation and RT-PCR. Expression of mRNA of WT1 $17 \mathrm{AA}(+)$ and 17AA(-) isoforms was determined as described previously (12). In brief, total RNA was isolated using Isogen (Wako, Osaka Japan) and reverse transcribed using murine Moloney leukemia virus (M-MLV) reverse transcriptase accoding to the manufacturer's instructions 


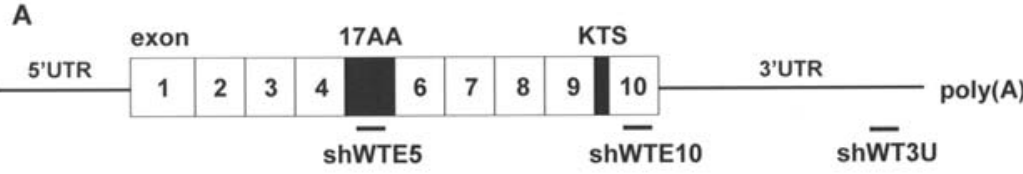

B

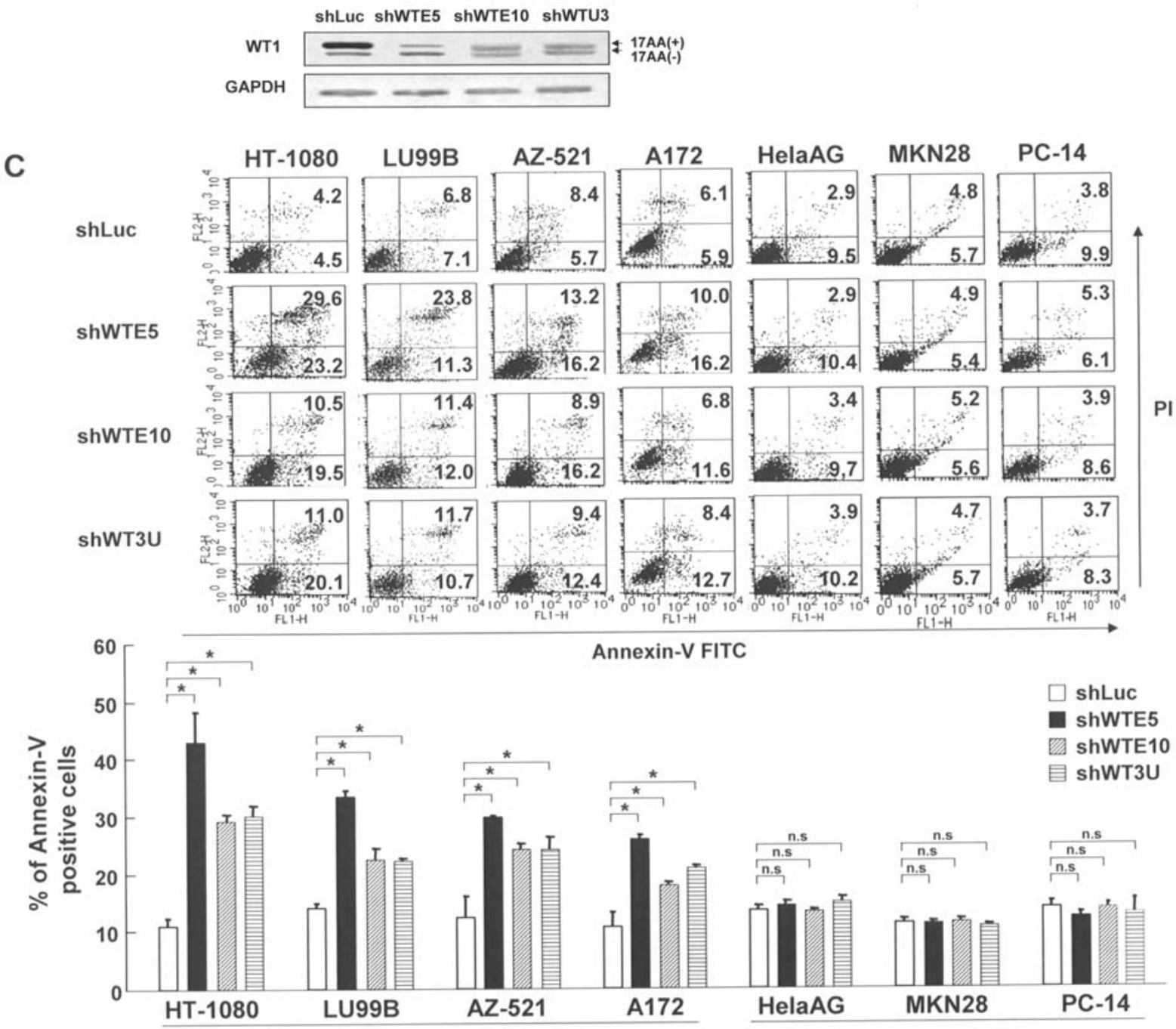

WT1 expression :

$(+)$

$(-)$

Figure 1. Knockdown of WT1 17AA(+) isoforms induces apoptosis in WT1-expressing solid cancer cells. (A) The schema of the WT1 mRNA. Three shRNAs targeting Exon 5, Exon 10 and 3'UTR of WT1 17AA(+) isoforms (shWTE5, shWTE10 and shWT3U) were constructed. (B) Knockdown of expression of WT1 17AA(+) isoforms by WT1-shRNA in HT-1080 cells. Expression of WT1 17AA(+) and 17AA(-) mRNA was examined by RT-PCR. 17AA(+), WT1 17AA(+) isoforms; and 17AA(-), WT1 17AA(-) isoforms. (C) One each of the three WT1-shRNAs or control shRNA (shLuc) was transfected into four WT1-expressing solid cancer cell lines (HT-1080, LU99B, AZ-521 and A172) and three WT1-non-expressing ones (HelaAG, MKN28 and PC-14). (C, upper panel) Representative dot plots of PI-Annexin V two-color flow cytometric analysis. (C, lower panel) Percentages of Annexin V-positive apoptotic cells were determined by PI-Annexin V two-color flow cytometry. Shown are average and standard error of three independent experiments. ${ }^{*} \mathrm{p}<0.05$; n.s, not significant.

(Promega, Madison, WI). PCR was performed for 25 cycles $\left(94^{\circ} \mathrm{C}\right.$ for $60 \mathrm{sec} / 60^{\circ} \mathrm{C}$ for $60 \mathrm{sec} / 72^{\circ} \mathrm{C}$ for $\left.90 \mathrm{sec}\right)$ using primer pairs jumping 17AA coding sequence. Sequences of the primers were as follows; forward primer, 5'-GACCTGG AATCAGATGAA-3'; and reverse primer, 5'-GAGAACTTT CGCTGACAAGTT-3'.

Analysis of apoptosis by flow cytometry. To assess apoptotic cells, $1 \times 10^{5}$ cells were washed with PBS, and stained with
Annexin V-fluorescein isothiocyanate (FITC) and propidium iodide (PI) at room temperature for $15 \mathrm{~min}$ in the dark using MEBCYTO Apoptosis Kit (Medical and Biological Laboratories Co., Ltd, Aichi, Japan) according to the manufacturer's instructions. Then, the stained cells were analyzed by FACScan flow cytometer (Becton-Dickinson, San Jose, CA). Frequency of Annexin V-positive apoptotic cells was shown as percentages of apoptotic cells to the total number of counted cells. 


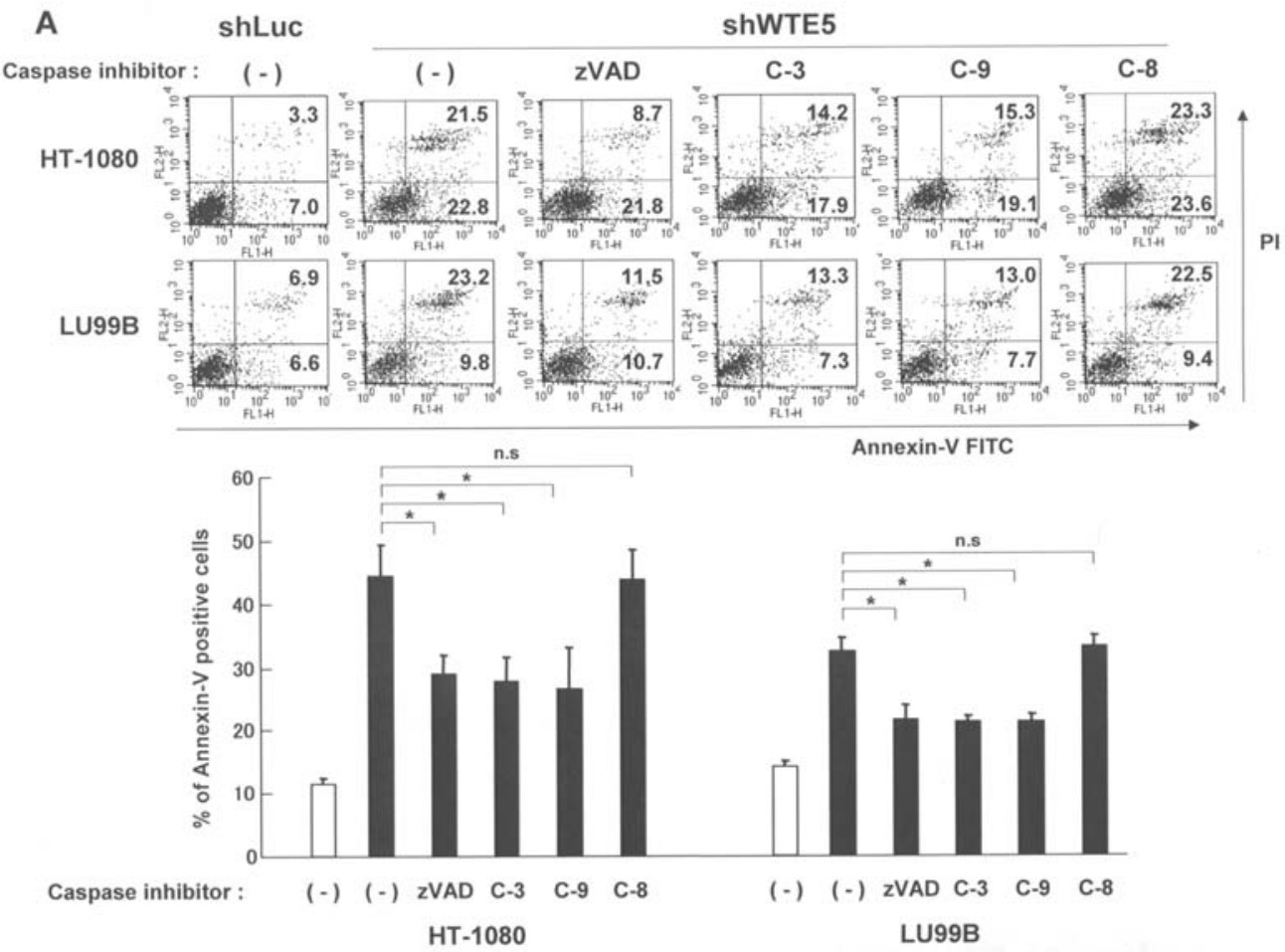

B
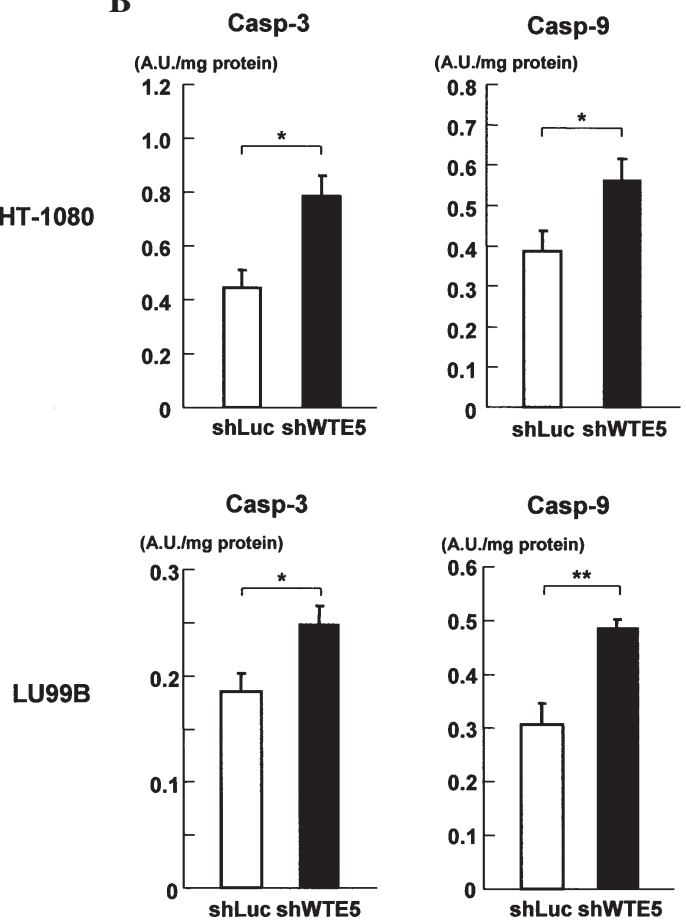

Figure 2. shWTE5 activates the intrinsic apoptosis pathway and induces mitochondrial damage. (A) shWTE5 or control shRNA (shLuc) was transfected into HT-1080 and LU99B cells in the presence or absence of broad caspase inhibitor (zVAD-fmk), caspase-3 inhibitor (Ac-DEVD-CHO), caspase-9 inhibitor (Ac-LEHD-CHO), and caspase-8 inhibitor (Ac-IETDCHO). zVAD, pan-caspase inhibitor zVAD-fmk; C-3, Ac-DEVD-CHO; C-9, Ac-LEHD-CHO; and C-8, Ac-IETD-CHO. (A, upper panel) Representative dot plots of PI-Annexin V two-color flow cytometric analysis. (A, lower panel) Percentages of Annexin V-positive apoptotic cells determined by PIAnnexin V two-color flow cytometry. (B) Activation of caspases by WT1shRNA. shWTE5 or shLuc was transfected into HT-1080 and LU99B cells. Caspase-3 and -9 activities were measured by fluorometric assay using Ac-DEVD-AFC and FAM-LEHD-FMK, respectively, as substrates. (A-C) Open column, control shLuc-transfected cells; closed column, shWTE5trancefected cells. Shown are average and standard error of three independent experiments. ${ }^{*} \mathrm{p}<0.05 ;{ }^{* *} \mathrm{p}<0.01 ; \mathrm{n} . \mathrm{s}$, not significant.

Activity of caspase. Activities of caspase-3 and -9 were measured as described previously (38). Briefly, the cells were collected $48 \mathrm{~h}$ after the transfection of shRNA vector, lysed in lysis buffer $(150 \mathrm{mM} \mathrm{NaCl}, 50 \mathrm{mM}$ Tris- $\mathrm{HCl}$, $\mathrm{pH}$ 7.4, $1 \mathrm{mM}$ EDTA, 0.1\% Triton-X) on ice for $30 \mathrm{~min}$ and centrifuged. The supernatant was stored at $-20^{\circ} \mathrm{C}$ until use. Concentration of proteins was determined using Bio-Rad protein assay reagent by Bradford method. Then, the cytosol containing $50 \mathrm{mg}$ of proteins was solved in reaction buffer (50 mM Tris-HCl, pH 7.4, 1 mM EDTA and 10 mM EGTA) containing $10 \mathrm{mM}$ of the enzyme substrate Ac-DEVD-AFC (for caspase-3 activity) or FAM-LEHD-FMK (for caspase-9 activity) and incubated at $37^{\circ} \mathrm{C}$ for $1 \mathrm{~h}$. Fluorescence at $485 / 535 \mathrm{~nm}$ was measured using a Spectra-Max Gemini XS fluorescence plate reader (Molecular Devices, Sunnyvale, CA).

Determination of cytochrome c release. To assess the release of cytochrome c from mitochondria to cytoplasm, cells were washed once with PBS, lysed in ice-cold STE buffer (250 $\mathrm{mM}$ sucrose, $25 \mathrm{mM}$ Tris- $\mathrm{HCl} \mathrm{pH} 6.8$, and $1 \mathrm{mM}$ EDTA), and immediately centrifuged at 15,000 rpm for $15 \mathrm{~min}$. The supernatants were mixed with an equal volume of $2 \mathrm{X}$ Laemmli's SDS sample buffer for Western blot analysis and stored at $-20^{\circ} \mathrm{C}$ until use.

Analysis of mitochondrial membrane potential loss. Changes in mitochondrial membrane potential following induction of apoptosis were assessed using MitoLight apoptosis detection kit (Chemicon International) according to the manufacturer's instructions. In brief, after induction of apoptosis, cells were incubated at $37^{\circ} \mathrm{C}$ for $15 \mathrm{~min}$ in reaction buffer containing MitoLight mitochondrial dye that stained mitochondria in 


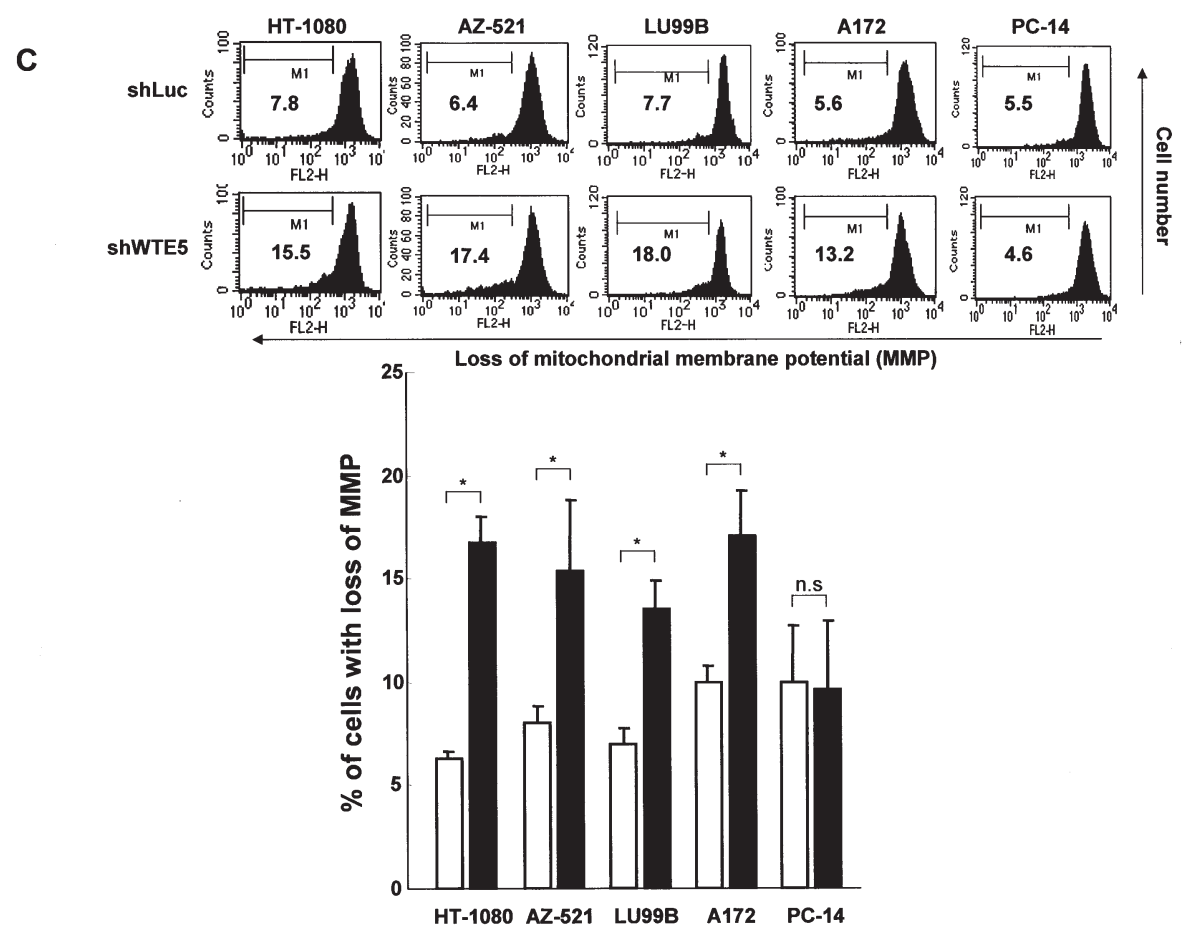

Figure 2. shWTE5 activates the intrinsic apoptosis pathway and induces mitochondrial damage. (C) shWTE5 or shLuc was transfected into four WT1expressing cancer cell lines (HT-1080, AZ-521, LU99B and A172) and WT1-non-expressing one (PC-14). Percentages of cells with loss of MMP were determined by flow cytometry. (A-C) Open column, control shLuc-transfected cells; closed column, shWTE5-trancefected cells. Shown are average and standard error of three independent experiments. ${ }^{*} \mathrm{p}<0.05 ;{ }^{*} \mathrm{p}<0.01 ; \mathrm{n} . \mathrm{s}$, not significant.

living cells in a membrane potential-dependent fashion. Then, mitochondrial membrane potential was analyzed using a FACScan flow cytometer in the FL2 channel.

Construction of expression vectors and transfection. A pcDNA 3.1(+) expression vector (Invitrogen, Carlsbad, CA) containing either of two human WT1 17AA(+) isoforms $[17 \mathrm{AA}(+) / \mathrm{KTS}(+)$ and $17 \mathrm{AA}(+) / \mathrm{KTS}(-)]$ was constructed (34). The vectors were linearized with PvuI and introduced into HT-1080 cells by electroporation using Gene Pulsor II (BioRad). The cells were cultured in the medium containing $700 \mu \mathrm{g} / \mathrm{ml}$ of G-418 and resistant cell clones were isolated.

Statistical analysis. The statistical significance in a difference between arithmetical means of test groups was assessed by unpaired t-test.

\section{Results}

Knockdown of WT1 17AA(+) isoforms induces apoptosis in WT1-expressing solid tumor cells. To knockdown the expression of WT1 17AA(+) isoforms, three shRNAs targeting different sites of WT1 17AA(+) isoforms (WT1shRNAs) were constructed (Fig. 1A). They included shRNAs that targeted exon 5 (shWTE5), exon 10 (shWTE10) and 3'UTR (shWT3U). Both shWTE10 and shWT3U recognized all the four WT1 isoforms while shWTE5 can target discriminatively $17 \mathrm{AA}(+)$ isoforms among four WT1 isoforms. To examine the ability of knockdown of the expression of WT1 $17 \mathrm{AA}(+)$ isoforms, one each of the three WT1-shRNAs (shWTE5, shWTE10 and shWT3U) or a control shRNA targeting Luciferase (shLuc) was transfected into WT1- expressing HT-1080 fibrosarcoma cells. After $48 \mathrm{~h}$ of culture, expression of WT1 mRNA was examined by RT-PCR. As shown in Fig. 1B, in shWTE5-transfected cells, expression of WT1 17AA(+) isoforms but not WT1 17AA(-) ones, was significantly decreased at mRNA levels. On the other hand, in shWTE10- or shWT3U-transfected cells, expression of both WT1 17AA(+) and 17AA(-) isoforms was suppressed.

Next, to determine which of WT1-shRNAs most effectively can induce apoptosis in solid cancer cells and be a potent anti-cancer agent, one each of the three WT1-shRNAs or a control shLuc was transfected into four different WT1expressing cancer cell lines (HT-1080, LU99B, AZ-521 and A172) and three different WT1-non-expressing cancer cell lines (HelaAG cervical, MKN28 gastric and PC-14 lung cancer cell lines), and the cells were cultured for $48 \mathrm{~h}$, and then analyzed for apoptosis. PI-Annexin V two-color flow cytometry showed that all the three WT1-shRNAs induced apoptosis in four WT1-expressing cancer cells, but not in three WT1-non-expressing cancer cells (Fig. 1C). Among the three WT1-shRNAs examined, shWTE5 could most effectively induce apoptosis in all the WT1-expressing cell lines examined. Thus, shWTE5 was intensively assessed the potential as an anti-cancer agent in the following experiments.

shWTE5 activates intrinsic apoptosis pathway and induces mitochondrial damage. To examine which of the apoptosis pathway is activated by suppression of expression of WT1 17AA(+) isoforms, both WT1-expressing HT-1080 and LU99B cells that were transfected with shWTE5 or shLuc were cultured for $48 \mathrm{~h}$ in the presence or absence of caspase inhibitors and examined for apoptosis (Fig. 2A). PI-Annexin V 
A

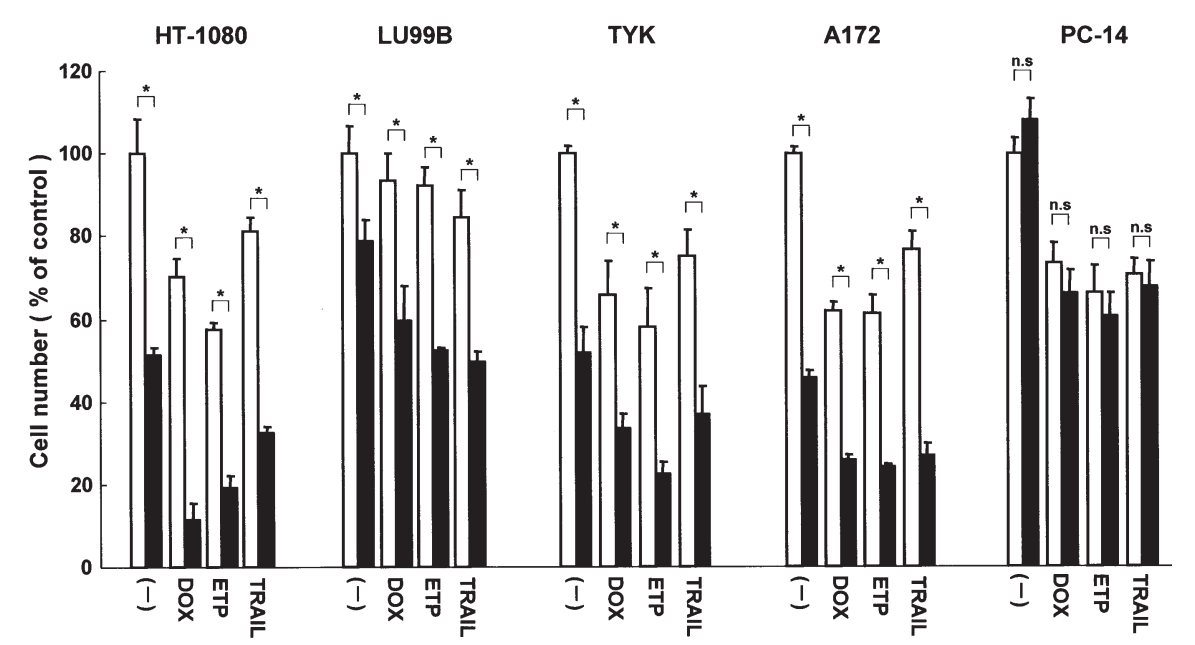

B
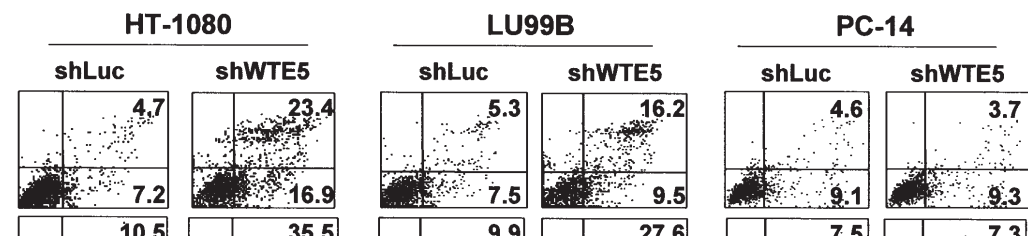

$(-)$
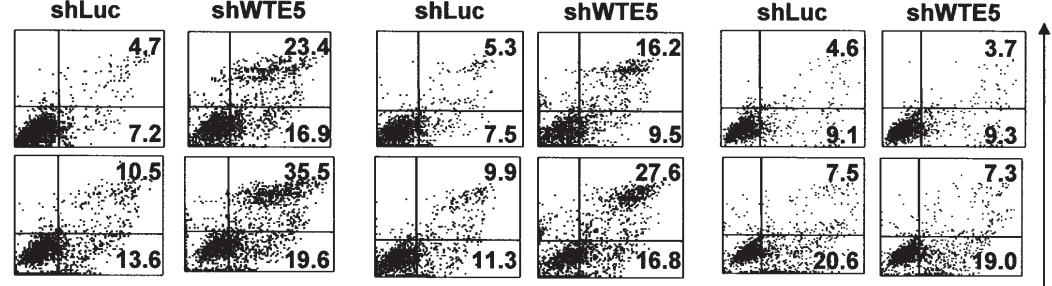

ETP

TRAIL
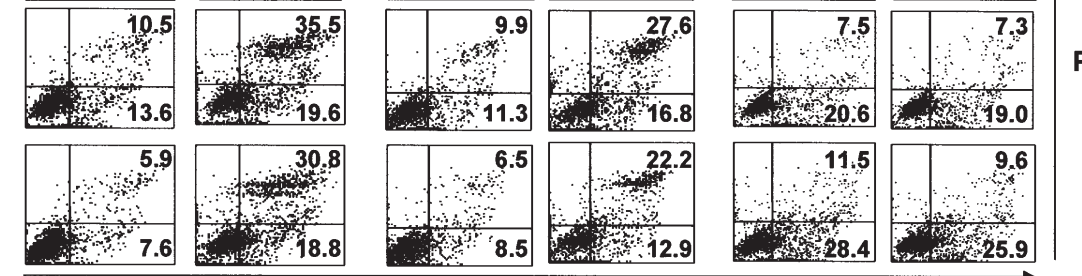

PI

C

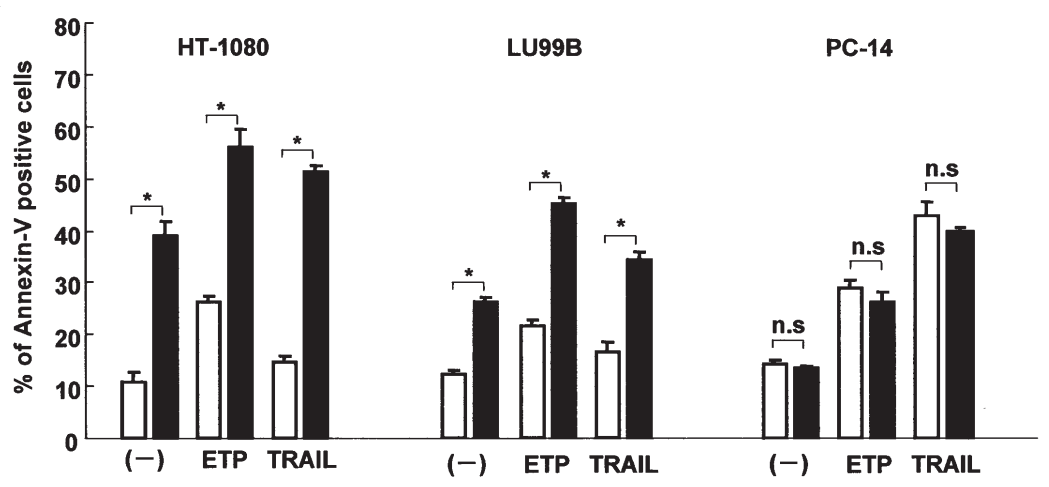

Figure 3. shWTE5 enhances chemotherapeutic agent- and TRAIL-induced apoptosis. Four different types of WT1-expressing solid tumor cells (HT-1080, LU99B, TYK and A172) and WT1-non-expressing ones (PC-14) were transfected with shWTE5 or shLuc and then treated with chemotherapeutic agents, DOX, ETP, or TRAIL for $24 \mathrm{~h}$. (A) shWTE5 enhances cell death induced by chemotherapy or TRAIL. Cell number was determined by counting the viable cells with the dye exclusion method. Shown are average and standard error of three independent experiments for each combination. (B and C) shWTE5 enhances ETP or TRAIL-induced apoptosis. Apoptosis was determined by PI-Annexin V two-color flow cytometry. (B) Representative dot plots of flow cytometric analysis. (C) Percentages of Annexin V-positive apoptotic cells were determined by flow cytometry. Shown are average and standard error of three independent experiments. (A and C) Open column, control shLuc-transfected cells; closed column, shWTE5-transfected cells. " $\mathrm{p}<0.05$. n.s, not significant.

two-color flow cytometry showed that pan-caspase inhibitor, zVAD-fmk, significantly inhibited the shWTE5-induced apoptosis in both HT-1080 and LU99B cells, indicating that shWTE5 induced apoptosis in a caspase-dependent manner. Block of apoptogenic signals either by a caspase 3-inhibitor, Ac-DEVD-CHO at a point where the intrinsic and extrinsic apoptosis pathways met, or by a caspase 9-inhibitor, AcLEHD-CHO at a point downstream of the mitochondria in the intrinsic pathway, not completely but significantly inhibited shWTE5-induced apoptosis in both HT-1080 and LU99B cells. On the other hand, block of apoptogenic signals by a caspase 8-inhibitor, Ac-IETD-CHO at a point in 
the extrinsic pathway did not inhibit the shWTE5-induced apoptosis in the two cell lines. These results indicated that shWTE5 activated the intrinsic but not extrinsic apoptosis pathway in WT1-expressing cancer cells.

To confirm the activation of the intrinsic apoptosis pathway by suppression of expression of WT1 17AA(+) isoforms, activities of caspase- 3 and -9 were examined by fluorometric assay $48 \mathrm{~h}$ after transfection of shWTE5. Activities of caspase-3 and -9 were significantly increased in both shWTE5-transfected HT-1080 and LU99B cells compared to control shLuc-transfected ones (Fig. 2B).

Moreover, to examine whether knockdown of expression of WT1 17AA(+) isoforms induces mitochondrial damage, shWTE5 was transfected into the four WT1-expressing cancer cell lines (HT-1080, AZ-521, LU99B and A172) and WT1-non-expressing one (PC-14). After $48 \mathrm{~h}$ of culture, the cells were analyzed for mitochondrial membrane potential (MMP) by flow cytometry. As shown in Fig. 2C, shWTE5 induced loss of MMP in all the four WT1-expressing cancer cell lines, but not in WT1-non-expressing one. These results indicated that WT1-shRNA activated the intrinsic apoptosis pathway through induction of mitochondrial damage in WT1expressing cancer cells.

shWTE5 enhances chemotherapeutic agent-and death ligand-induced apoptosis. To examine whether or not shWTE5 enhances apoptosis induced by chemotherapeutic agents or death ligand in various types of cancers cells, shWTE5 or control shLuc was tranfected into four WT1expressing cancer cell lines (HT-1080, LU99B, TYK and A172) and WT1-non-expressing one (PC-14). After $48 \mathrm{~h}$ of culture, these cells were treated with chemotherapeutic agents, doxorubicin (DOX) and etoposide (ETP) that activated the intrinsic apoptosis pathway, or with death ligand TRAIL that mainly activated the extrinsic apoptosis pathway for $24 \mathrm{~h}$. As shown in Fig. 3A, shWTE5 significantly enhanced cell death induced by DOX, ETP or TRAIL in all the four WT1expressing cell lines examined, but not in WT1-nonexpressing lung cancer cells. Annexin V-PI two-color flow cytometry confirmed that shWTE5 significantly enhanced apoptosis induced by ETP or TRAIL in WT1-expressing HT1080 and LU99B cells, but not in WT1-non-expressing PC-14 cells (Fig. 3B and C). These results showed that shWTE5 enhanced chemotherapy- and TRAIL-induced apoptosis in WT1-expressing cancer cells.

shWTE5 enhances chemotherapeutic agent- and death ligand induced mitochondrial damage. To examine whether shWTE5 enhanced mitochondrial damage induced by chemotherapeutic agents, DOX and ETP, or death ligand TRAIL, shWTE5 or shLuc was transfected into WT1expressing HT-1080 cells and WT1-non-expressing PC-14 cells. After $48 \mathrm{~h}$ of culture, the cells were treated with DOX, ETP, or TRAIL for $24 \mathrm{~h}$ and analyzed for loss of MMP by flow cytometry. shWTE5 significantly enhanced loss of MMP induced by chemotherapeutic agents, DOX and ETP, or TRAIL in WT1-expressing HT-1080 cells, but not in nonWT1-expressing PC-14 cells (Fig. 4A and B). Moreover, Western blot analysis showed that release of cytochrome $\mathrm{c}$ from mitochondria induced by combination of shWTE5 with one each of DOX, ETP and TRAIL was 4.2, 2.5, and 2.2 times higher than that induced by a combination of the shLuc with respective agents in HT-1080 cells (Fig. 4C). These results indicated that suppression of WT1 17AA(+) isoforms by shWTE5 enhanced mitochondrial damage induced by chemotherapeutic agents or by death ligand TRAIL.

Overexpression of WT1 $17 A A(+)$ isoform prevents mitochondrial damage induced by ETP or TRAIL and inhibits apoptosis. To confirm the antiapoptotic functions of WT1 17AA(+) isoforms, the targets of shWTE5, HT-1080 cell clones transduced with one each of WT1 17AA(+) isoforms [17AA(+)KTS(+) and 17AA(+)KTS(-)] were generated, then treated with ETP or TRAIL for $24 \mathrm{~h}$, and analyzed for mitochondrial damage and apoptosis (Fig. 5A). PI-Annexin V two-color flow cytometry showed that transduced-expression of one each of WT1 17AA(+) isoforms significantly inhibited both ETP- and TRAIL-induced apoptosis (Fig. 5B). Flow cytometric and Western blot analysis showed the prevention of ETP- or TRAIL-induced loss of MMP by transduction of one each of WT1 17AA(+) isoforms and the inhibition of cytochrome c release from mitochondria, respectively (Fig. 5C and D). Taken together, these results indicated that both WT1 17AA(+) isoforms had antiapoptotic functions, prevented mitochondrial membrane damages and inhibited apoptosis induced by ETP or TRAIL.

shWTE5 changed the expression profile of Bcl-2 gene family members. Since Bcl-2 gene family member proteins played an important role in mitochondrial damage in the process of apoptosis, it was examined whether expression of these proteins was changed by shWTE5. shWTE5 or control shLuc was transfected into WT1-expressing HT-1080 cells and WT1non-expressing PC-14 cells. After $48 \mathrm{~h}$ of culture, expression of Bcl-2 gene family member proteins was examined by Western blot analysis. As shown in Fig. 6, suppression of WT1 17AA(+) isoforms by shWTE5 increased proapoptotic Bak and Bax and decreased antiapoptotic Bcl-2 and Bcl-xL at protein levels. On the other hand, in WT1-non-expressing PC-14 cells, transfection of shWTE5 did not induce any change in expression levels of Bcl-2 gene family member proteins. These results indicate that WT1 isoforms with exon 5 might play an antiapoptotic role through regulation of $\mathrm{BCl}-2$ family genes.

\section{Discussion}

Accumulating findings indicated that the WT1 gene played an oncogenic role in tumorigenesis of various kinds of cancers (32). Recently, we demonstrated an antiapoptotic function of WT1 17AA(+) isoforms [17AA(+)KTS(+) and 17AA(+)KTS(-)] through stabilization of mitochondrial membrane potential in human leukemia cells (37). In the present study, we demonstrated that knockdown of expression of WT1 17AA(+) isoforms by WT1-shRNA induced mitochondrial damage and the resultant apoptosis in WT1expressing solid tumor cells originated from gastric, lung, and ovarian cancers, fibrosarcoma and glioblastoma. Present and previous results of ours indicated that WT1 17AA(+) 
A

HT-1080
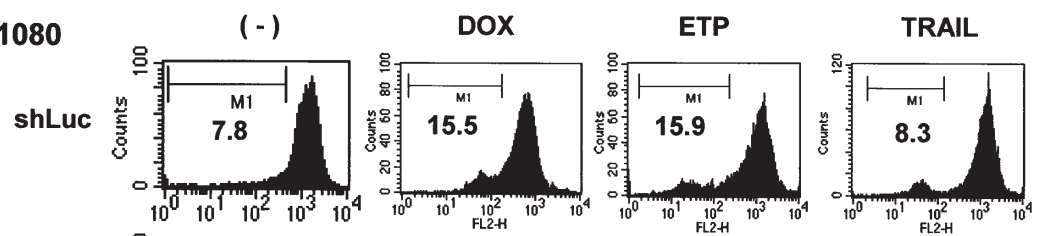

ShWTE5
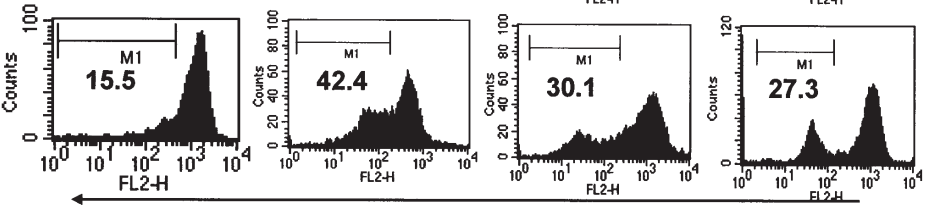

PC-14

$(-)$

DOX

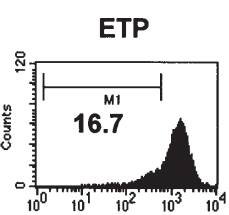

TRAIL
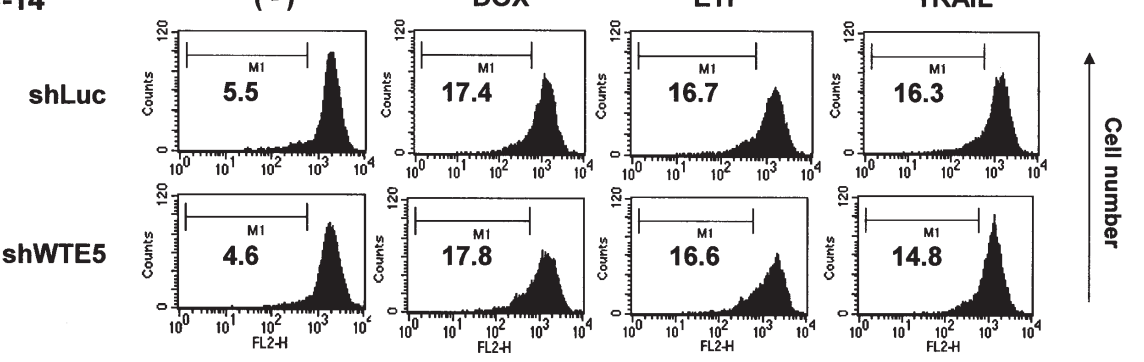

B shWTE5
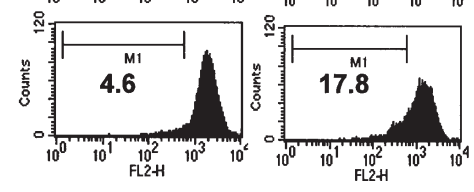

Loss of MMP

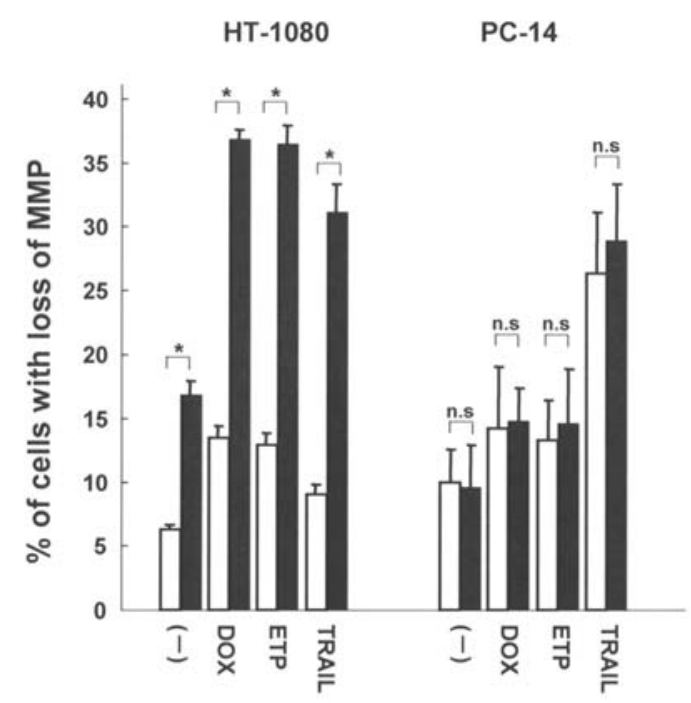

C

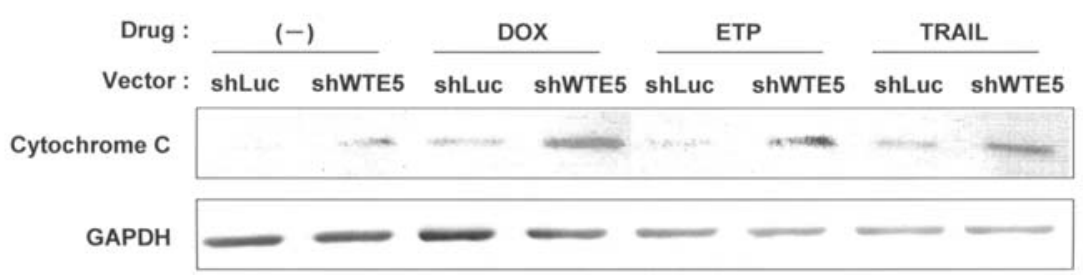

Figure 4. shWTE5 enhances chemotherapeutic agent- and TRAIL-induced mitochondrial damage. shWTE5 or shLuc was transfected into WT1-expressing HT-1080 cells and WT1-non-expressing PC-14 cells. After 48 h of culture, cells were treated with DOX, ETP, or TRAIL. (A) Representative results of histogram from flow cytometric analysis for loss of MMP. (B) Percentages of cells with loss of MMP are shown. Shown are average and standard error of three independent experiments. Open column, shLuc-transfected cells; closed column, shWTE5-transfected cells. "p<0.05; n.s., not significant. (C) Representative results of Western blot showing mitochondrial cytochrome c release in HT-1080 cells induced by a combination of shWTE5 or control shLuc and one each of DOX, ETP and TRAIL.

isoforms played an antiapoptotic role in not only leukemia cells but also in various types of solid tumor cells and thus that WT1 17AA(+) isoforms should be promising targets of molecular-targeting therapy against both leukemia and solid tumors.
In the current practice of anti-cancer therapy, the majority of solid tumors are considerably resistant to drug-based cytotoxic therapy. Since the effectiveness of cytotoxic therapy primarily depends on the ability to induce apoptosis in tumor cells, conquest of their resistance to apoptosis is a key to 
A

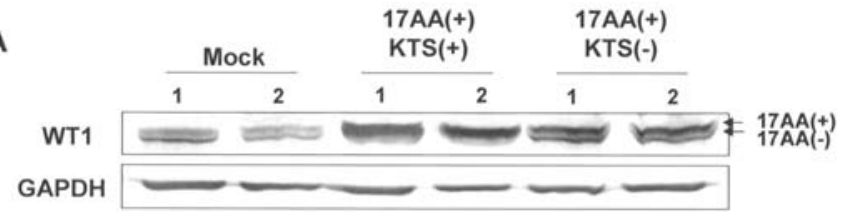

B

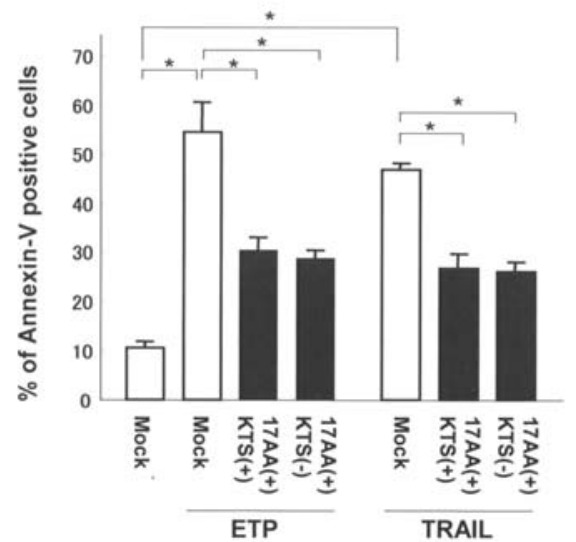

C

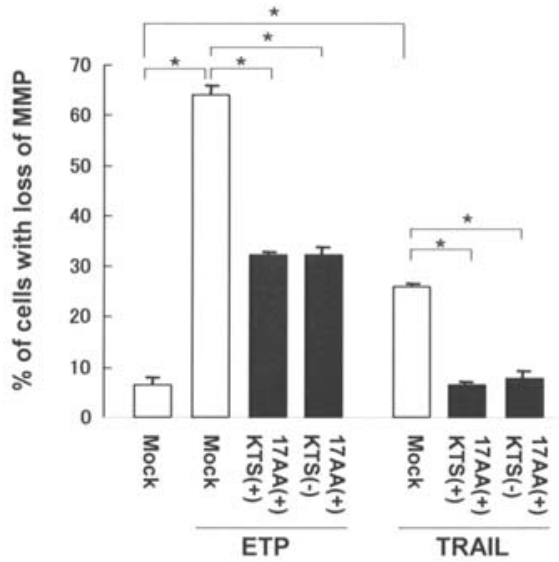

D

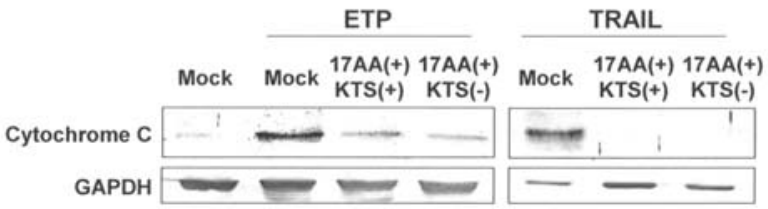

Figure 5. Constitutive expression of WT1 17AA(+) isoforms inhibits mitochondrial damage and apoptosis induced by chemotherapeutic agents and TRAIL. (A) Establishment of HT-1080 cell clones transduced with either of two WT1 17AA(+) isoforms. Expression of WT1 17AA(+) and 17AA(-) proteins were examined by Western blot analysis. (B-D) Inhibition of mitochondrial damage and apoptosis by transduced expression of WT1 $17 \mathrm{AA}(+)$ isoforms. HT-1080 cell clones transduced with either of two WT1 17AA(+) isoforms or mock expression vector were treated with ETP (50 $\mu \mathrm{M})$ or TRAIL (50 ng/ml) for $24 \mathrm{~h}$ and analyzed for mitochondrial damage. Experiments were independently performed three times using two different cell clones for each WT1 isoforms or mock expression vector. "p<0.05. (B) Apoptosis induced by ETP or TRAIL was analyzed by PI-Annexin V two-color flow cytometry. Shown are average and standard error of Annexin V-positive apoptotic cells in two different HT-1080 cell clones that were transduced with either of WT1 17AA(+) isoforms or control vector. (C) Loss of MMP induced by ETP or TRAIL was analyzed by flow cytometry. Shown are average and standard error of percentages of cells with loss of MMP in two different HT-1080 cell clones for each WT1 17AA(+) isoform or mock expression vector. (D) Mitochondrial release of cytochrome c in HT-1080 cell clones treated with ETP or TRAIL was analyzed by Western blot. (A-D) Mock, mock expression pcDNA 3.1(+) vector-transduced clones; KTS(+), WT1 17AA(+)KTS(+) isoform-transduced clones and KTS(-), WT1 17AA(+)KTS(-) isoform-transduced ones.

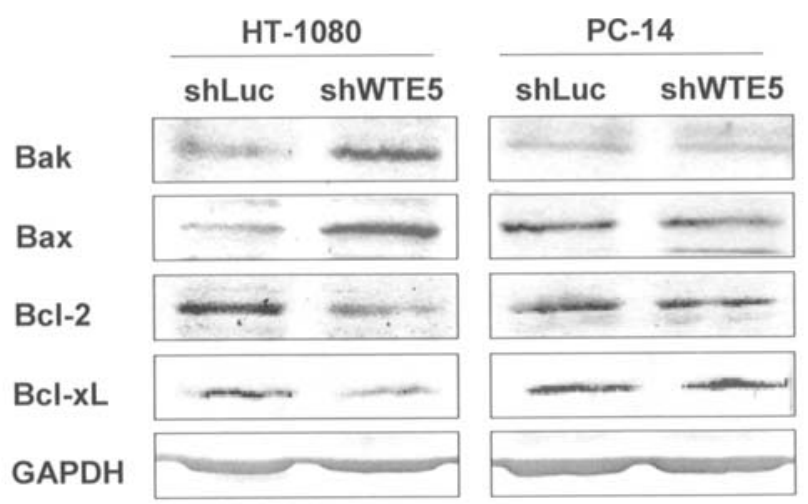

Figure 6. shWTE5 changes expression profile of Bcl-2 gene family member proteins. shWTE5 or shLuc was transfected into HT-1080 and PC-14 cells. After $48 \mathrm{~h}$ of culture, cells were analyzed for the expression of Bcl-2 gene family member proteins, Bak, Bax, Bcl-2 and Bcl-xL by Western blot.

develop more effective anti-cancer therapy. Present study showed that WT1-shRNA potently induced mitochondrial damage in solid tumor cells. In combination with chemotherapeutic agents (DOX and ETP) whose apoptosisinducing activities were essentially dependent on the mitochondrial damage and the resultant activation of the intrinsic apoptosis pathway, WT1-shRNA promoted loss of mitochondrial membrane potential and enhanced apoptosis in fibrosarcoma, lung and ovarian cancer, and glioblastoma cells. It was also shown that WT1-shRNA enhanced apoptosis induced by death ligand TRAIL whose actions largely depended on the activation of the extrinsic apoptosis pathway in the same four solid tumor cells. Promotion of mitochondrial damage by WT1-shRNA leading to additive activation of the intrinsic apoptosis pathway is considered to enhance the apoptosis-inducing activity of the death ligand TRAIL. Therefore, WT1-shRNA has a potential to enhance apoptosis induced not only by chemotherapeutic agents (activators of intrinsic apoptosis pathway) but also by death ligand (activator of extrinsic apoptosis pathway).

The apoptotic process induced by WT1-shRNA was associated with increased expression of proapoptotic Bak and Bax proteins and decreased expression of antiapoptotic Bcl-2 and Bcl-xL proteins. Since Bcl-2 gene family member proteins play an important role in control of the mitochondrial damage, the results shown here may indicate that WT1 $17 \mathrm{AA}(+)$ isoforms exert their antiapoptotic function through regulation of expression of $\mathrm{Bcl}-2$ gene family member proteins and that WT1-shRNA-induced changes of expression profile of these proteins lead to promotion of mitochondrial damage induced by chemotherapeutic agents, DOX or ETP, or death ligand TRAIL in WT1-expressing cancers.

In conclusion, WT1 $17 \mathrm{AA}(+)$ isoforms are promising targets of molecular targeting therapy against both leukemia 
and solid tumors and shRNA targeting exon 5 of the WT1 gene (shWTE5) should serve as a potent anti-cancer agent against both the malignancies.

\section{Acknowledgments}

This work was supported in part by a Grant-in Aid from the Ministry of Education, Science, Sports and Culture and the Ministry of Health, Labour and Welfare, Japan.

\section{References}

1. Call KM, Glaser TM, Ito CY, Buckler AJ, Pelletier J, Haber DA, Rose EA, Kral A, Yeger H, Lewis WH, Jones C and Housman DE: Isolation and characterization of a zinc finger polypeptide gene at the human chromosome 11 Wilms' tumor locus. Cell 60: 509-520, 2000.

2. Gashler AL, Bonthron DT, Madden SL, Rauscher FJ III, Collins T and Sukhatme VP: Human platelet-derived growth factor A chain is transcriptionally repressed by the Wilms' tumor suppressor WT1. Proc Natl Acad Sci USA 89: 10984-10988, 1992.

3. Harrington MA, Konicek B, Song A, Xia XL, Fredericks WJ and Rauscher FJ III: Inhibition of colony-stimulating factor-1 promoter activity by the product of the Wilms' tumor locus. J Biol Chem 268: 21271-21275, 1993.

4. Drummond IA, Madden SL, Rohwer-Nutter P, Bell GI, Sukhatme VP and Rauscher FJ III: Repression of the insulinlike growth factor II gene by the Wilms' tumor suppressor WT1. Science 257: 674-678, 1992.

5. Werner H, Re GG, Drummond IA, Sukhatme VP, Rauscher FJ III, Sens DA, Garvin AJ, LeRoith D and Roberts CT Jr: Increased expression of the insulin-like growth factor I receptor gene, IGF1R, in Wilms' tumor is correlated with modulation of IGF1R promoter activity by the WT1 Wilms' tumor gene product. Proc Natl Acad Sci USA 90: 5828-5832, 1993.

6. Goodyer P, Dehbi M, Torban E, Bruening W and Pelletier J: Repression of the retinoic acid receptor-alpha gene by the Wilms' tumor suppressor gene product, wt1. Oncogene 10: 1125-1129, 1995.

7. Lee SB, Huang K, Palmer R, Truong VB, Herzlinger D, Kolquist KA, Wong J, Paulding C, Yoon SK, Gerald W, Oliner JD and Haber DA: The Wilms' tumor suppressor WT1 encodes a transcriptional activator of amphiregulin. Cell 98: 663-673, 1999.

8. Larsson SH, Charlieu JP, Miyagawa K, Engelkamp D, Rassoulzadegan M, Ross A, Cuzin F, van Heyningen V and Hastie ND: Subnuclear localization of WT1 in splicing or transcription factor domains is regulated by alternative splicing. Cell 81: 391-401, 1995.

9. Davies RC, Calvio C, Bratt E, Larsson SH, Lamond AI and Hastie ND: WT1 interacts with the splicing factor U2AF65 in an isoform-dependent manner and can be incorporated into spliceosomes. Genes Dev 12: 3217-3225,1998.

10. Niksic M, Slight J, Sanford JR, Caceres JF and Hastie ND: The Wilms' tumour protein (WT1) shuttles between nucleus and cytoplasm and is present in functional polysomes. Hum Mol Genet 13: 463-471, 2004.

11. Inoue K, Sugiyama H, Ogawa H, Nakagawa M, Yamagami T, Miwa H, Kita K, Hiraoka A, Masaoka T, Nasu K, Kyo T, Dohy H, Nakauchi H, Ishidate T, Akiyama T and Kishimoto T: WT1 as a new prognostic factor and a new marker for the detection of minimal residual disease in acute leukemia. Blood 84: 3071-3079, 1994.

12. Oji Y, Miyoshi S, Maeda H, Hayashi S, Tamaki H, Nakatsuka S, Yao M, Takahashi E, Nakano Y, Hirabayashi H, Shintani Y, Oka Y, Tsuboi A, Hosen N, Asada M, Fujioka T, Murakami M, Kanato K, Motomura M, Kim EH, Kawakami M, Ikegame K, Ogawa H, Aozasa K, Kawase I and Sugiyama H: Overexpression of the Wilms' tumor gene WT1 in de novo lung cancers. Int J Cancer 100: 297-303, 2002.

13. Oji Y, Yamamoto H, Nomura M, Nakano Y, Ikeba A, Nakatsuka S, Abeno S, Kiyotoh E, Jomgeow T, Sekimoto M, Nezu R, Yoshikawa Y, Inoue Y, Hosen N, Kawakami M, Tsuboi A, Oka Y, Ogawa H, Souda S, Aozasa K, Monden M and Sugiyama H: Overexpression of the Wilms' tumor gene WT1 in colorectal adenocarcinoma. Cancer Sci 94: 712-717, 2003.
14. Oji Y, Yano M, Nakano Y, Abeno S, Nakatsuka S, Ikeba A, Yasuda T, Fujiwara Y, Takiguchi S, Yamamoto H, Fujita S, Kanato K, Ito K, Jomgeow T, Kawakami M, Tsuboi A, Shirakata T, Nishida S, Hosen N, Oka Y, Aozasa K, Monden M and Sugiyama H: Overexpression of the Wilms' tumor gene WT1 in esophageal cancer. Anticancer Res 24: 3103-3108, 2004.

15. Loeb DM, Evron E, Patel CB, Sharma PM, Niranjan B, Buluwela L, Weitzman SA, Korz D and Sukumar S: Wilms' tumor suppressor gene (WT1) is expressed in primary breast tumors despite tumor-specific promoter methylation. Cancer Res 61: 921-925, 2001.

16. Miyoshi Y, Ando A, Egawa C, Taguchi T, Tamaki Y, Tamaki H, Sugiyama H and Noguchi S: High expression of Wilms' tumor suppressor gene predicts poor prognosis in breast cancer patients. Clin Cancer Res 8: 1167-1171, 2002.

17. Oji Y, Miyoshi Y, Koga S, Nakano Y, Ando A, Nakatsuka S, Ikeba A, Takahashi E, Sakaguchi N, Yokota A, Hosen N, Ikegame K, Kawakami M, Tsuboi A, Oka Y, Ogawa H, Aozasa K, Noguchi S and Sugiyama H: Overexpression of the Wilms' tumor gene WT1 in primary thyroid cancer. Cancer Sci 94: 606-611, 2003.

18. Oji Y, Nakamori S, Fujikawa M, Nakatsuka S, Yokota A, Tatsumi N, Abeno S, Ikeba A, Takashima S, Tsujie M, Yamamoto H, Sakon M, Nezu R, Kawano K, Nishida S, Ikegame K, Kawakami M, Tsuboi A, Oka Y, Yoshikawa K, Aozasa K, Monden M and Sugiyama H: Overexpression of the Wilms' tumor gene WT1 in pancreatic ductal adenocarcinoma. Cancer Sci 95: 583-587, 2004.

19. Oji Y, Inohara H, Nakazawa M, Nakano Y, Akahani S, Nakatsuka S, Koga S, Ikeba A, Abeno S, Honjo Y, Yamamoto Y, Iwai S, Yoshida K, Oka Y, Ogawa H, Yoshida Y, Aozasa K, Kubo T and Sugiyama H: Overexpression of the Wilms' tumor gene WT1 in head and neck squamous cell carcinoma. Cancer Sci 94: 523-529, 2003.

20. Oji Y, Suzuki T, Nakano Y, Maruno M, Nakatsuka S, Jomgeow T, Abeno S, Tatsumi N, Yokota A, Aoyagi S, Nakazawa T, Ito K, Kanato K, Shirakata T, Nishida S, Hosen N, Kawakami M, Tsuboi A, Oka Y, Aozasa K, Yoshimine T and Sugiyama H: Overexpression of the Wilms' tumor gene W T1 in primary astrocytic tumors. Cancer Sci 95: 822-827, 2004.

21. Ueda T, Oji Y, Naka N, Nakano Y, Takahashi E, Koga S, Asada M, Ikeba A, Nakatsuka S, Abeno S, Hosen N, Tomita Y, Aozasa K, Tamai N, Myoui A, Yoshikawa H and Sugiyama H: Overexpression of the Wilms' tumor gene WT1 in human bone and soft-tissue sarcomas. Cancer Sci 94: 271-276, 2003.

22. Sotobori T, Ueda T, Oji Y, Naka N, Araki N, Myoui A, Sugiyama $\mathrm{H}$ and Yoshikawa $\mathrm{H}$ : Prognostic significance of Wilms' tumor gene (WT1) mRNA expression in soft tissue sarcoma. Cancer 106: 2233-2240, 2006.

23. Harada Y, Nonomura N, Nishimura K, Tamaki H, Takahara S, Miki T, Sugiyama H and Okuyama A: WT1 gene expression in human testicular germ-cell tumors. Mol Urol 3: 357-364, 1999.

24. Yamagami T, Ogawa H, Tamaki H, Oji Y, Soma T, Oka Y, Tatekawa T, Tsuboi A, Kim EH, Akiyama T and Sugiyama H: Suppression of Wilms' tumor gene (WT1) expression induces G2/M arrest in leukemic cells. Leuk Res 22: 383-384, 1998.

25. Algar EM, Khromykh T, Smith SI, Blackburn DM, Bryson GJ and Smith PJ: A WT1 antisense oligonucleotide inhibits proliferation and induces apoptosis in myeloid leukaemia cell lines. Oncogene 12: 1005-1014, 1996.

26. Oji Y, Ogawa H, Tamaki H, Oka Y, Tsuboi A, Kim EH, Soma T, Tatekawa T, Kawakami M, Asada M, Kishimoto T and Sugiyama H: Expression of the Wilms' tumor gene WT1 in solid tumors and its involvement in tumor cell growth. Jpn J Cancer Res 90: 194-204, 1999.

27. Inoue $\mathrm{K}$, Tamaki H, Ogawa H, Oka Y, Soma T, Tatekawa T, Oji Y, Tsuboi A, Kim EH, kawakami M, Akiyama T, Kishimoto T and Sugiyama H: Wilms' tumor gene (WT1) competes with differentiation-inducing signal in hematopoietic progenitor cells. Blood 91: 2969-2976, 1998.

28. Tsuboi A, Oka Y, Ogawa H, Elisseeva OA, Tamaki H, Oji Y, Kim EH, Soma T, Tatekawa T, Kawakami M, Kishimoto T and Sugiyama H: Constitutive expression of the Wilms' tumor gene WT1 inhibits the differentiation of myeloid progenitor cells but promotes their proliferation in response to granulocyte-colony stimulating factor (G-CSF). Leuk Res 23: 499-505, 1999.

29. Osaka M, Koami K and Sugiyama T: WT1 contributes to leukemogenesis: expression patterns in 7,12-dimethyl-benz[a]anthracene (DMBA)-induced leukemia. Int J Cancer 72: 696-699, 1997. 
30. Li H, Oka Y, Tsuboi A, Yamagami T, Miyazaki T, Yusa S, Kawasaki K, Kishimoto Y, Asada M, Nakajima H, Kanato K, Nishida S, Masuda T, Murakami M, Hosen N, Kawakami M, Ogawa H, Melchers F, Kawase I, Oji Y and Sugiyama H: The lck promoter-driven expression of the Wilms' tumor gene WT1 blocks intrathymic differentiation of T-lineage cells. Int J Hematol 77: 463-470, 2003.

31. Jomgeow T, Oji Y, Tsuji N, Ikeda Y, Ito K, Tsuda A, Nakazawa T, Tatsumi N, Sakaguchi N, Takashima S, Shirakata T, Nishida S, Hosen N, Kawakami M, Tsuboi A, Oka Y, Itoh K and Sugiyama H: Wilms' tumor gene WT1 17AA(-)/KTS(-) isoform induces morphological changes and promotes cell migration and invasion in vitro. Cancer Sci 97: 259-270, 2006.

32. Sugiyama H: Wilms' tumor gene WT1: its oncogenic function and clinical application. Int J Hematol 73: 177-187, 2001

33. G Klein: Cancer, apoptosis and non-immune surveillance. Cell Death Differentiation 11: 13-17, 2004.

34. Leech SH, Olie RA, Gautschi O, Simoes-Wust AP, Tschopp S, Haner R, Hall J, Stahel RA and Zangemeister-Wittke U: Induction of apoptosis in lung-cancer cells following Bcl-xL anti-sense treatment. Int J Cancer 86: 570-576, 2000.
35. Alsabeh R, Wilson CS, Ahn CW, Vasef MA and Battifora $\mathrm{H}$ Expression of Bcl-2 by breast cancer: a possible diagnostic application. Mod Pathol 9: 439-444, 1996.

36. Hofmann HS, Simm A, Hammer A, Silber RE and Bartling B: Expression of inhibitors of apoptosis (IAP) proteins in nonsmall cell human lung cancer. J Cancer Res Clin Oncol 128 554-560, 2002

37. Ito K, Oji Y, Tatsumi N, Shimizu S, Kanai Y, Nakazawa T, Asada M, Jomgeow T, Aoyagi S, Nakano Y, Tamaki H, Sakaguchi N, Shirakata T, Nishida S, Kawakami M, Tsuboi A, Oka Y, Tsujimoto Y and Sugiyama H: Antiapoptotic function of 17AA(+)WT1 (Wilms' tumor gene) isoforms on the intrinsic apoptosis pathway. Oncogene 25: 4217-4229, 2006.

38. Shimizu S, Eguchi Y, Kamiike W, Matsuda H and Tsujimoto $Y$ : Bcl-2 expression prevents activation of the ICE protease cascade. Oncogene 12: 2251-2257, 1996. 